Boise State University

ScholarWorks

9-12-2006

\title{
Imaging Complex Structure in Shallow Seismic-reflection Data Using Prestack Depth Migration
}

John H. Bradford

Boise State University

Lee M. Liberty

Boise State University

Mitchell W. Lyle

Boise State University

William P. Clement

Boise State University

Scott Hess

Boise State University 


\title{
Case History
}

\section{Imaging complex structure in shallow seismic-reflection data using prestack depth migration}

\author{
John H. Bradford ${ }^{1}$, Lee M. Liberty ${ }^{1}$, Mitch W. Lyle ${ }^{1}$, William P. Clement ${ }^{1}$, and Scott Hess ${ }^{1}$
}

\begin{abstract}
Prestack depth migration (PSDM) analysis has the potential to significantly improve the accuracy of both shallow seismic reflection images and the measured velocity distributions. In a study designed to image faults in the Alvord Basin, Oregon, at depths from 25-1000 m, PSDM produced a detailed reflection image over the full target depth range. In contrast, poststack time migration produced significant migration artifacts in the upper $100 \mathrm{~m}$ that obscured reflection events and limited the structural interpretation in the shallow section. Additionally, an abrupt increase from $\sim 2500$ to $>3000 \mathrm{~m} / \mathrm{s}$ in the PSDM velocity model constrained the interpretation of the transition from sedimentary basin fill to basement volcanic rocks. PSDM analysis revealed a complex extensional history with at least two distinct phases of basin growth and a midbasin basement high that forms the division between two major basin compartments.
\end{abstract}

\section{INTRODUCTION}

While both time and depth poststack migration methods are often applied to shallow seismic reflection data (Davies and King, 1992; Bradford et al., 1998; Liberty, 1998; Wiederhold et al., 1998), prestack depth migration (PSDM) has some inherent advantages. First, it is important to recognize that poststack migration imaging is implicitly limited by the assumptions of NMO processing. These assumptions include approximately horizontal reflectors, small offsetto-depth ratio, and small lateral and vertical velocity gradients, all of which are commonly violated in shallow reflection surveys. Although dip-moveout (DMO) processing is a means of dealing with the problem of dipping reflectors (Deregowski, 1985; Hale, 1991;
Bradford et al., 1998), the latter two assumptions remain limiting factors. The process of PSDM, coupled with migration velocity analysis, produces both a migrated image and a depth-velocity model that are not subject to the assumptions of NMO processing. Thus, one of the most important advantages of PSDM is improved image accuracy and detailed velocity models that can provide valuable constraints in interpretation. In addition, PSDM suppresses steeply dipping, coherent noise such as ground roll or air waves (Bradford and Sawyer, 2002), can suppress migration artifacts by stacking after migration, and can be formulated to include surface topography in the migration. All of these advantages are well known as PSDM has become a standard part of the processing flow in hydrocarbon exploration data processing (see THE LEADING EDGE special issues on migration - June 2005; December 2002; May 2001). Yet, with the exception of a few examples in the literature (Pasasa et al., 1998; Bradford and Sawyer, 2002; Morozov and Levander, 2002), PSDM remains a rarely utilized processing tool in shallow seismic reflection.

The processing stream for PSDM analysis includes random and coherent noise suppression, depth-velocity model estimation, PSDM, and postmigration stacking. Of these steps, the most critical is velocity model estimation as PSDM is strongly sensitive to the accuracy of the velocity model. For PSDM velocity analysis, the data are sorted into common-image-point (CIP) gathers in the postmigrated domain, analogous to common midpoint (CMP) gathers in stacking velocity analysis. When the velocity model is correct, reflectors in the CIP domain are flat. Often the model must be updated iteratively to produce a good migration result. A typical approach is layer stripping, where the velocity model is updated layer by layer in a top-to-bottom sequence (Al-Yahya, 1989; Lafond and Levander, 1993).

Alternatively, we may estimate the model using reflection tomography. In recent years, tomography has become the preferred method for velocity model building (Guo and Fagin, 2002). Stork (1992)

Manuscript received by the Editor July 11, 2005; revised manuscript received March 6, 2006; published online September 21, 2006.

${ }^{1}$ Boise State University, CGISS MG-206, 1910 University Drive, Boise, Idaho 83725. E-mail: johnb@cgiss.boisestate.edu; 1ml@cgiss.boisestate.edu; mitch@cgiss.boisestate.edu; johnb@cgiss.boisestate.edu; billc@cgiss.boisestate.edu; scotthess@cgiss.boisestate.edu. (C) 2006 Society of Exploration Geophysicists. All rights reserved. 
presents a method of reflection tomography in the postmigration domain. Depth deviations are measured as residual moveout (RMO) in the CIP gathers. The depth deviations are converted to traveltime deviations using the velocity above a given reflector. The tomographic inversion is formulated to minimize the traveltime deviations along key horizons in the CIP domain with the sensitivity matrix computed via ray tracing. We have found this method to be robust in both shallow seismic and ground-penetrating radar (GPR) data analysis (Bradford, 2006). The inversion result is constrained in a variety of ways. For example, in this study, the solution was constrained to linear vertical gradients between reflecting horizons, and the algorithm allows for velocity discontinuities across constraint zone boundaries.

Our objective is to demonstrate that PSDM can, in some cases, significantly improve shallow seismic reflection images relative to poststack migration. Specifically, we use both methods to image an active extensional basin where target depths vary from $25 \mathrm{~m}$ to more than $1000 \mathrm{~m}$ and therefore span the range typically considered to fall within the realm of shallow seismic reflection. We use a typical $\mathrm{NMO} / \mathrm{DMO}$ processing flow to produce the poststack migrated image, and the reflection tomography approach described above to produce the PSDM section.

\section{FIELD SETTING AND DATA ACQUISITION}

The Borax Lake Hydrothermal System (BLHS), consisting of Borax Lake and a series of linear trending hot springs, is located near the center of Pueblo Valley in the Alvord Basin of southeast Oregon (Figure 1). Alvord Basin is a north-south-trending graben in the northern basin and range province bounded on the east and west sides by north-trending normal faults (Pezzopane and Weldon, 1993; Blewitt et al., 2003). Hemphill-Haley (1987) documented recent deformation $(<2000$ year BP) along the basin bounding fault

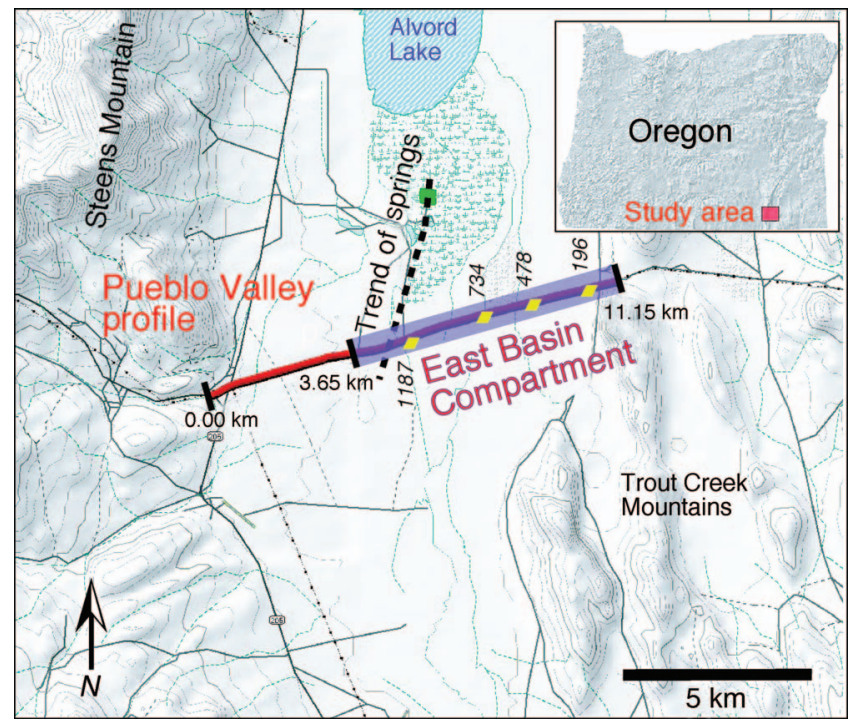

Figure 1. Map of the study area. The trace of the Borax Lake Fault (BLF) zone was mapped from the location of hot springs and the break in surface topography and is indicated with a dashed line. The section of the Pueblo Valley profile acquired over the East Basin Compartment is discussed in the text. Distances along the profile are given for reference. Shot locations discussed in the text are indicated in yellow with shot-number annotation.

systems. The Steens and Pueblo Mountains bound the basin to the west and the Trout Creek Mountains lie along the eastern margin. The basin lies in the rain shadow of Steens Mountain, and the area receives the least precipitation in Oregon. Presently, Alvord Lake is an ephemeral playa located $3 \mathrm{~km}$ north of Borax Lake. During wetter climatic cycles over the past 20,000 years, Alvord Lake was a substantial water body covering much of Alvord Basin. Consequently, the basin fill consists primarily of unconsolidated lacustrine sediments overlying the Miocene basement rocks consisting of rhyolites, tuffs, and basalts (Fuller, 1931; Williams and Compton, 1953; Evans and Geisler, 2001). Depth of the basin fill is highly variable, with maximum thickness reaching $1000 \mathrm{~m}$ in places (Cleary et al., 1981).

Based on gravity data, topographic expression, and the linear trend of the series of springs that define the BLHS, previous workers have inferred that the BLHS is controlled by a north-south-trending, midbasin fault (Cleary et al., 1981; Fairley et al., 2003). We are using a number of geophysical techniques, including gravity, magnetics, and time-domain electromagnetics, to characterize the BLHS at scales ranging from $10^{1}$ to $10^{3} \mathrm{~m}$ (Hess et al., 2004). Here we discuss acquisition and processing of a $2 \mathrm{D}$ basin-scale seismic reflection profile. Our primary objectives are (1) to verify the presence of a significant fault zone beneath the BLHS and then (2) to develop the relationship between the midbasin fault zone and the basin-bounding faults.

As we will show, significant stratigraphic complexity occurs in the eastern part of the basin. Because of this complexity, we focus on the eastern $7.5 \mathrm{~km}$ of the Pueblo Valley profile (Figure 1) in the following discussion. Quaternary silts and fine-grained sands (Qs) form the surficial material along most of the profile. At the eastern margin, the topography rises sharply as the profile begins to climb the Trout Creek rangefront; here, the Tertiary volcanic rocks (Tv) are exposed and form the surface material. Lithified siltstone is outcropping approximately $1.5 \mathrm{~km}$ north of the Pueblo Valley profile along the trend of the BLHS springs. These rocks were encountered at depths of 300-400 $\mathrm{m}$ in boreholes drilled on either side of BLHS trend (unpublished Anadarko well logs), indicating a significant midbasin horst.

The primary criteria in survey design were imaging the basin fault system over the full thickness of the basin fill (up to $700 \mathrm{~m}$ ) while maintaining resolution of the near-surface structure $(<100 \mathrm{~m})$. Using our 120 channel seismograph with a relatively coarse $5-\mathrm{m}$ receiver spacing and a $12.5-\mathrm{m}$ off-end gap provided $607.5 \mathrm{~m}$ maximum offset (additional survey details are listed in Table 1). The off-

Table 1. Data acquisition parameters.

Recording instrument

Source

Geometry

Receiver array

Receiver spacing

Source spacing

Near offset

Far offset

Sampling interval
Geometrics, 24-bit, 120channel seismograph

400-lb accelerated weight drop, stack of four

End on, shooting east to west

$10-\mathrm{Hz}$ single geophones

$5 \mathrm{~m}$

$10 \mathrm{~m}$

$12.5 \mathrm{~m}$

$607.5 \mathrm{~m}$

$1 \mathrm{~ms}$ 
set-to-target depth ratio of nearly one provided good velocity control over the primary target range. The shallow water table $(<3 \mathrm{~m}$ over most of the survey area) resulted in relatively high velocity moveout $(>1400 \mathrm{~m} / \mathrm{s})$ of the early reflections. This allowed us to image reflections as shallow as $25 \mathrm{~m}$ with the relatively coarse receiver spacing. Thus, the geometry provided a reasonable compromise between good velocity control at depth and adequate fold for shallow reflections.

The damp silts and muds at the surface presented optimal source and receiver coupling conditions and produced relatively low-amplitude ground roll. Consequently, the data have a high $\mathrm{S} / \mathrm{N}$ ratio with clear reflections evident to $1.5 \mathrm{~s}$ (Figure 2). Immediately evident in the shot records are numerous reflectors with nonnormal moveout, indicating steeply dipping horizons, particularly at times a)

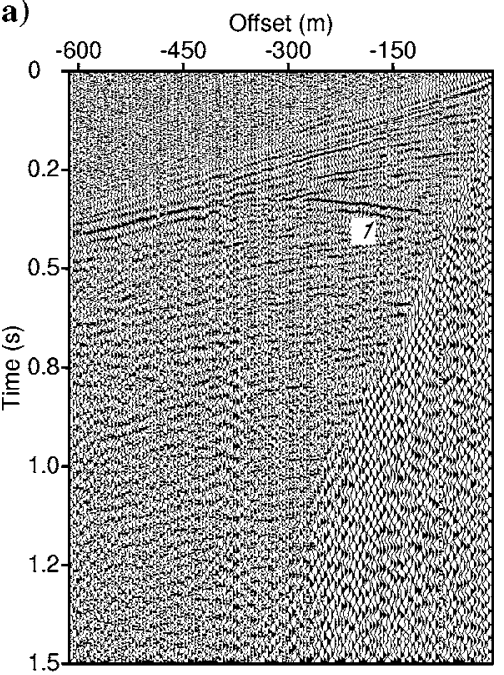

Shot 1187

c)

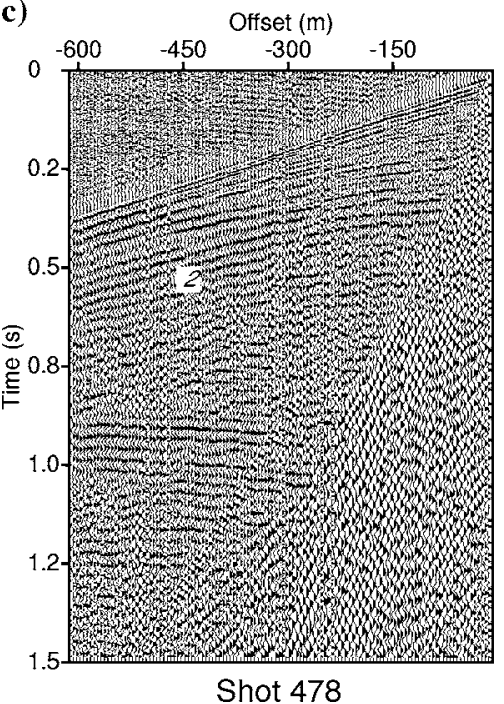

b)

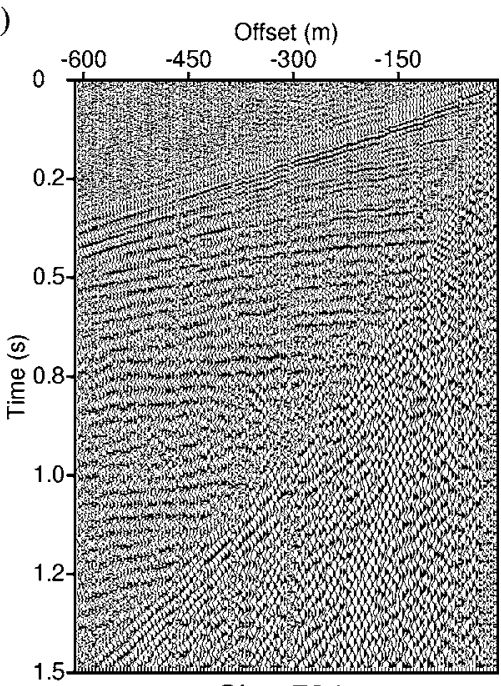

Shot 734

d)

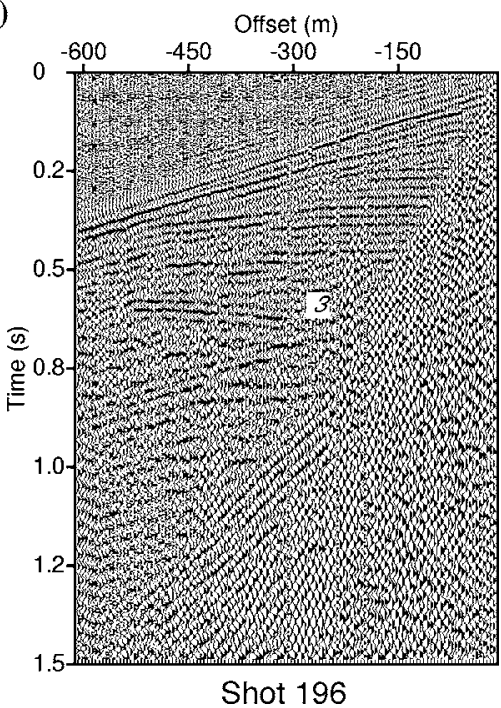

Figure 2. Shot gathers taken along the Pueblo Valley profile. Surface locations are indicated in Figure 1. Only a time-varying bandpass filter and AGC have been applied. Nonnormal moveout and conflicting dips indicate horizons dipping steeply in both directions. Note that shot numbers decrease from west to east. (label key: (1) Fault-plane diffraction, (2) Down-dip stratigraphic reflectors, (3) Intersection of back-dipping stratigraphic reflections and down-dipping fault plane diffractions). greater than $300 \mathrm{~ms}$. Events with very low apparent velocity indicate downdip shooting, whereas events with high or negative apparent velocity indicate updip shooting. Numerous updip and downdip events are evident, suggesting complex subsurface stratigraphy (Figure 2). Given the large depth range, data quality, and subsurface complexity, this data set provided a good test for the application of PSDM in shallow seismic reflection imaging.

\section{DATA PROCESSING}

Preprocessing for migration included a time-varying bandpass filter, automatic gain control (AGC), $f-k$ filtering, top muting the first arrival, and inside muting the strongly aliased coherent modes $(v$ $<200 \mathrm{~m} / \mathrm{s}$ ). Figure 3 details the processing parameters. This processing scheme attenuated near-offset coherent noise (e.g., ground roll) and optimized resolution in the near surface while preserving deep reflections. Because the primary objective of the study was geometric interpretation of the stratigraphy, we did not attempt to preserve amplitudes and applied AGC early in the flow to minimize contamination of the reflection image with high-amplitude coherent noise. We chose a datum elevation of $1250 \mathrm{~m}$. The datum was higher than the elevation along much of the profile but was necessary to image the shallowest reflections on the eastern margin where the elevation rose to just over $1260 \mathrm{~m}$. We completed all processing using Pro$\mathrm{MAX}^{\mathrm{TM}}$ data processing software.

We derived the starting depth-velocity model by iteratively applying dip moveout and stacking velocity analysis. After two iterations, there were no significant changes in the velocity model. Applying a $200-\mathrm{CMP} \times 200$-ms smoother to the stacking velocity model (Figure 4) prior to depth conversion via Dix inversion produced significantly better migration results than the unsmoothed model. In stacking velocity analysis, we could not clearly identify any deep reflections near the eastern basin-bounding fault. Thus, the basement rock velocity in this area was initially unconstrained and we extended the surface velocity to depth (Figure 4a).

For PSDM, we used a Kirchhoff method based on Deregowski's (1985) algorithm. The Green's functions were computed using a ray tracer that solves for the maximum amplitude arrivals and computes traveltimes for arbitrary source and receiver elevations. The program optionally computes amplitudes, but we did not use this functionality. We migrated the data from topography in the common offset domain.

After the first iteration of PSDM and reflection tomography using the method of Stork (1992), we interpreted depth to basement based on an abrupt increase in velocity from $\sim 2500$ to $>3000 \mathrm{~m} / \mathrm{s}$ and a change in reflector character from well-defined stratigraphic reflectors to discontinuous, irregular reflections. We then edited the velocity model to remove obvious tomogra- 


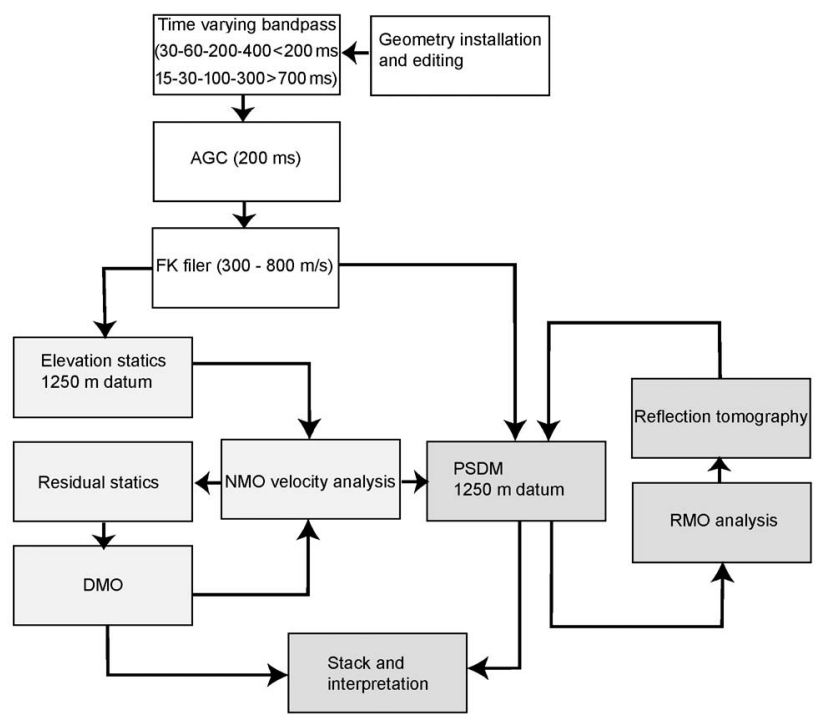

Figure 3. PSDM data processing flow. The left side of the diagram represents a conventional NMO processing scheme which produces the starting depth-velocity model. The right side of the diagram illustrates the steps to produce the final velocity model and PSDM image.
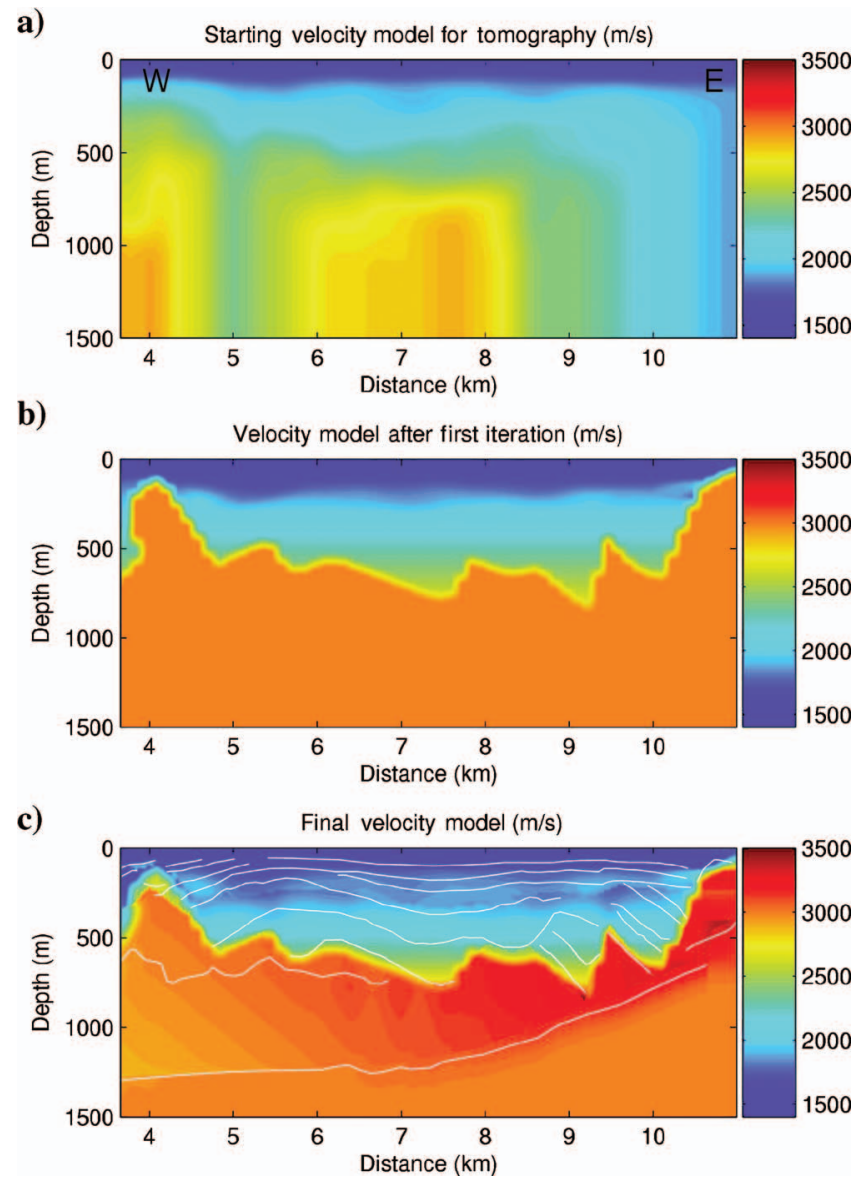

Figure 4. Changes in the migration-velocity model as it is refined through reflection tomography. (a) The smoothed stacking velocity model; (b) the model after one round of tomography and editing; and (c) the final velocity model. Note that horizons used to measure RMO are plotted on the final model and that no velocity editing was required after the final tomography iteration.
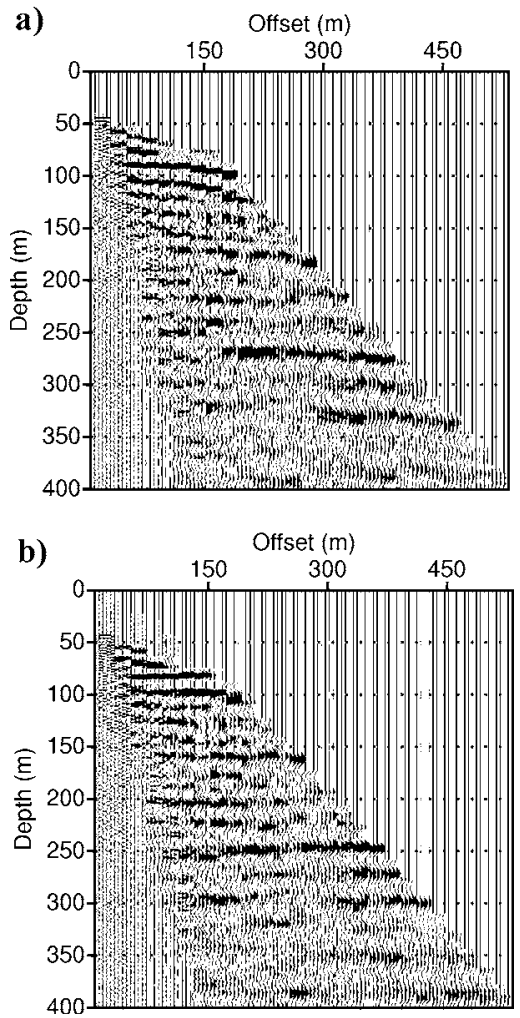

Figure 5. CIP gather at $6.15 \mathrm{~km}$ produced with (a) the starting depthvelocity model (Figure 4a) and (b) the final velocity model (Figure 4c). Panel (a) shows a significant positive RMO indicating a general velocity overestimate. In panel (b), RMO is largely removed. Note that the reflector depth positions are shallower because of the decrease in velocity values.

phy artifacts, particularly at depths greater than $700 \mathrm{~m}$ where velocities were not as well constrained because of a lack of laterally continuous reflections and offset-to-depth ratio $<1$. This edited velocity model (Figure $4 \mathrm{~b}$ ) was then the input for the second round of PSDM and tomography. After the second round of tomography (Figure 4c), no significant artifacts were evident, residual moveout was substantially reduced (Figure 5), and no additional editing was necessary to produce a good PSDM result (Figure 6). Note that the deep horizons within the high-velocity basement are not laterally continuous reflections but rather are linked segments of laterally discontinuous events that may or may not be a common physical boundary. Linking discontinuous events as a common horizon for the purpose of RMO analysis does not effect the tomographic result.

For comparison, we also migrated the NMO/DMO stacked section (Figure 6b) using a poststack Kirchhoff time migration algorithm (Figure 6c). The velocity distribution for poststack time migration was the smoothed stacking velocity model (the depth converted velocity distribution is shown in Figure 4a).

\section{Comparison of migration results}

With the exception of a few reflector mislocations where there are large lateral velocity contrasts, poststack time migration and PSDM produced similar results below $150 \mathrm{~ms}$ or approximately $110 \mathrm{~m}$ (Figure 6). However, the images in the shallow part of the basin differ dramatically. Migration artifacts in the poststack migrated image completely obscure the shallow reflections over much of the section. 
The migration artifacts are in part a result of the requirement of elevation datuming prior to poststack migration. Because we wanted to preserve as much of the shallow section as possible, the elevation at the center part of the east basin segment is below datum. This results in a data discontinuity that produces migration artifacts. The PSDM section is migrated from elevation, so the shallow artifacts are minimized. Additionally, artifacts that are present are attenuated through CIP stacking after PSDM. The overall result is that PSDM produces a much clearer image of the shallow structures.

The difference in image quality is particularly evident in zones A and B that are outlined in Figure 6. In zone A, the PSDM image clearly shows a minimum vertical displacement of $25 \mathrm{~m}$ across the Borax
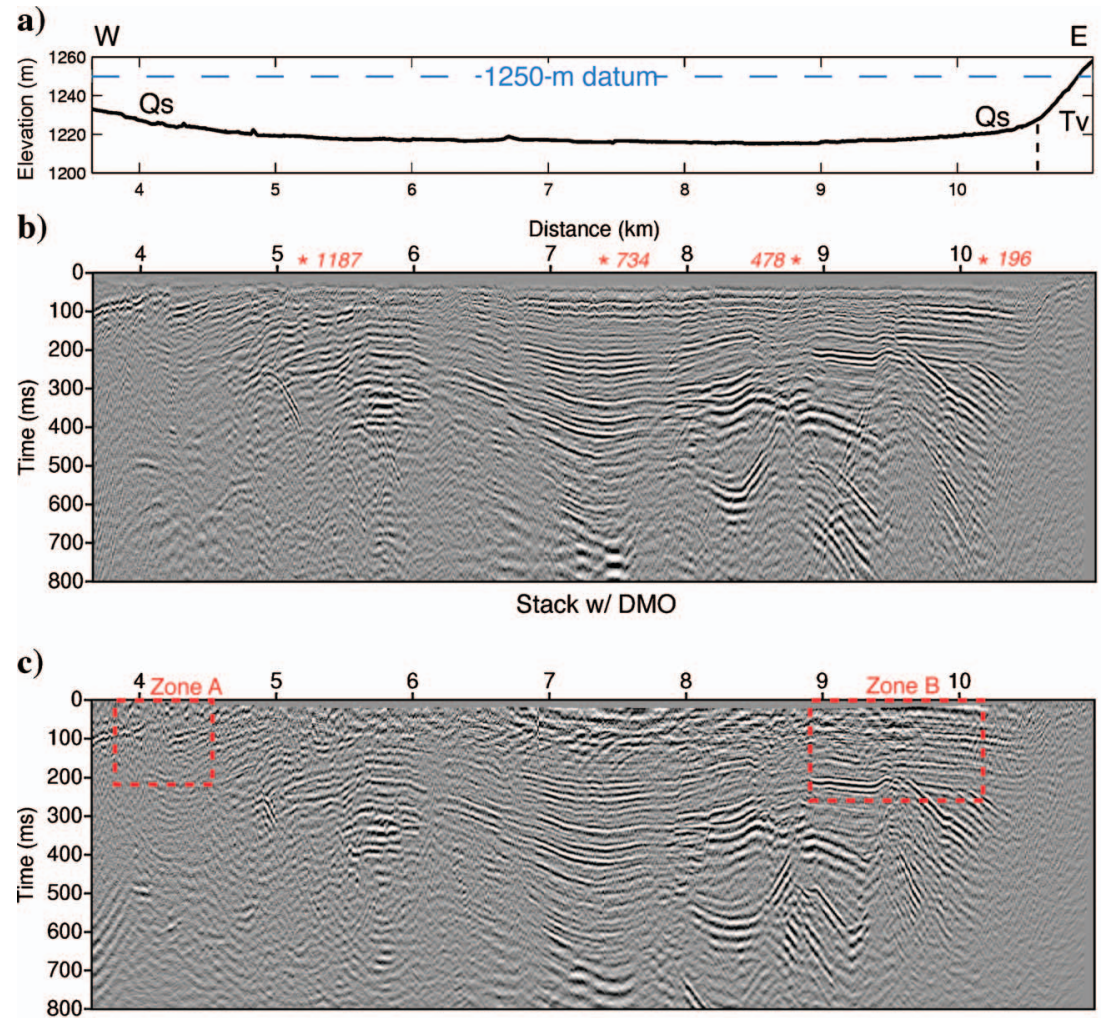

Poststack time migration

d)

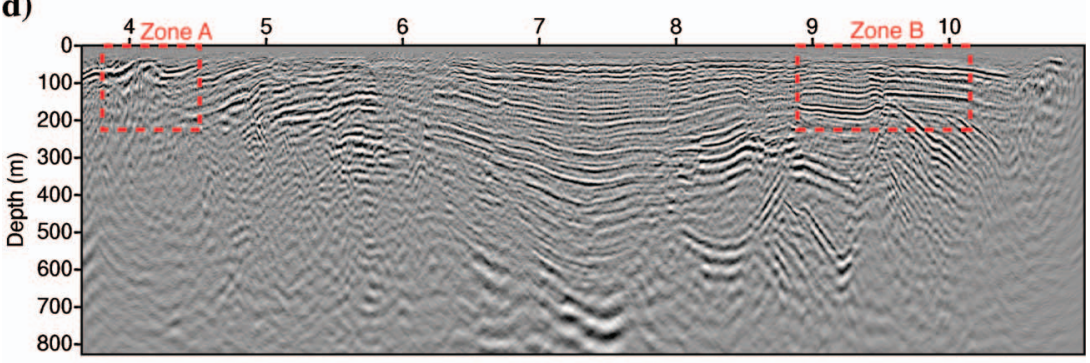

Prestack depth migration

Figure 6. The east basin segment of the Pueblo Valley profile. (a) Surface elevation along the seismic profile with surficial units indicated; (b) stack after two iterations of DMO and stacking velocity analysis with shots locations from Figures 1 and 2 indicated; (c) poststack Kirchhoff time migration with the stacking-velocity model shown in Figure 4a; (d) PSDM image using the velocity model shown in Figure 4c. Migration noise in the poststack migration obscures shallow reflections while PSDM produces a clear image from depths of less than $25 \mathrm{~m}$ to greater than $800 \mathrm{~m}$. Note in particular zones A and B which are highlighted with red boxes. (Qs - Quaternary silts and sands; Tv - Tertiary volcanics).

\section{STRUCTURAL INTERPRETATION}

We identify a basement high $(<100 \mathrm{~m}$ depth) that divides the Pueblo Valley into two subbasins. This interpretation is consistent with an earlier gravity interpretation that places a horst below the BLHS (Cleary et al., 1981). Our study highlights the structures observed across the eastern subbasin. Figure 8 shows a symmetric basin with near equal displacement along the eastern and western subbasin margins. The BLHS horst is located on the western edge of our profile and is bounded to the east by a set of $40^{\circ}$, east-dipping normal faults including the BLF. Along the eastern margin of the basin, we interpret a series of $30^{\circ}-45^{\circ}$ west-dipping normal faults, including the eastern basin bounding fault (EBBF). We also identify numerous smaller-offset faults distributed across the basin.

An angular unconformity is evident at a depth of $200 \mathrm{~m}$ between 9.5 and $10.5 \mathrm{~km}$ immediately west of the EBBF (Figures 7 and 8). Below this unconformity, strata dip steeply (up to $35^{\circ}$ ) and are truncated to the east by the EBBF. Progressively steeper dips on strata along the eastern margin of the basin suggest growth faulting and continued deformation during and after deposition. Above the unconformity, strata dip eastward $\sim 4^{\circ}$ and suggest faulting continued later than the age of the shallowest beds imaged. The unconformity likely represents a dry period when erosion replaced deposition. Although the unconformity may continue west of $9 \mathrm{~km}$, a lack of contrasting dips on strata with depth makes this horizon difficult to track.

Along the western margin of the subbasin, we measure $6^{\circ}$ dip to the west on shallow $(<100 \mathrm{~m}$ depth) strata that terminate at the BLF. This is a $50 \%$ increase in tilt of near-surface strata adjacent to the BLF, compared to strata adjacent to the EBBF. However, strata deeper in the basin appear more steeply dipping along the eastern basin margin. This suggests that displacements were initially greater along the eastern basin margin if the strata are approximately the same age with increasing depth. Strain may have shifted from the eastern margin to the BLF fault system during basin evolution. The presence of hot springs upon the central valley horst along the western bound- 
ary of our profile supports an active western subbasin fault system that likely includes the BLF.

There is tremendous variability in location and timing of faulting within the basin and range both regionally and locally (Wallace, 1984), and basin styles and fault patterns vary tremendously (Effimoff and Pinezich, 1981; Liberty et al., 1994). For example, in the nearby Quinn River Valley, recent faults have abandoned the basin margin and now appear within the central portions of the valley (Narwold, 2001; Personius and Mahan, 2005). Multiphase basin evolution has been documented on seismic profiles across basins within central Nevada, again suggesting transfer of strain from one
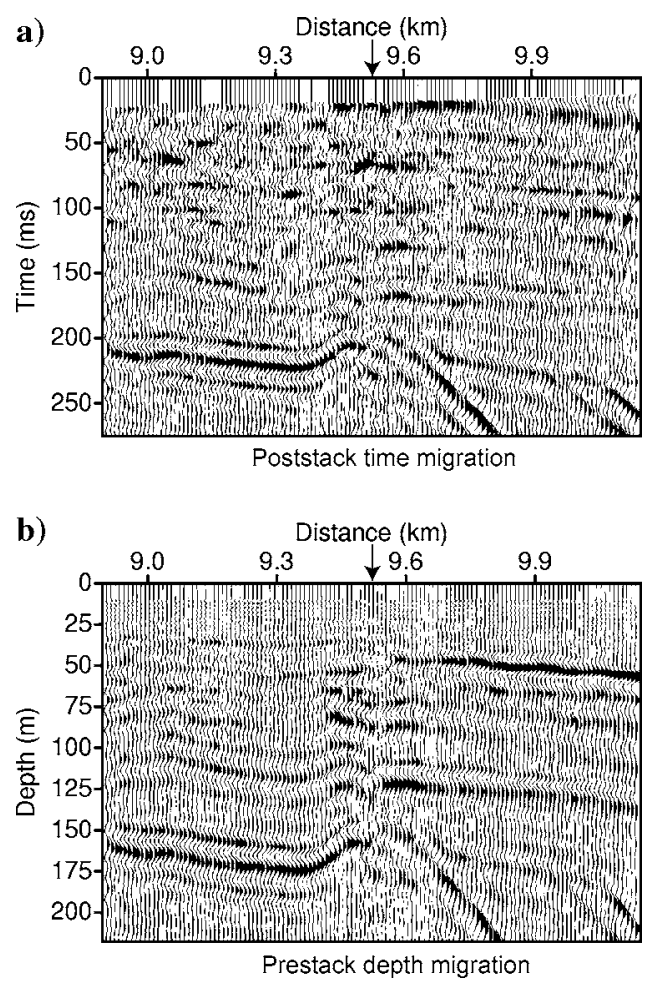

Figure 7. (a) Poststack time-migrated image of zone B in Figure 6 , and (b) zone B from the PSDM section. PSDM produces a clear image as shallow as $30 \mathrm{~m}$ where it is clear that the fault at $9.5 \mathrm{~km}$ shows near-surface reactivation with $<10 \mathrm{~m}$ of vertical offset. The reflections above $150 \mathrm{~ms}(110 \mathrm{~m})$ are completely obscured by migration noise in the poststack migrated section.

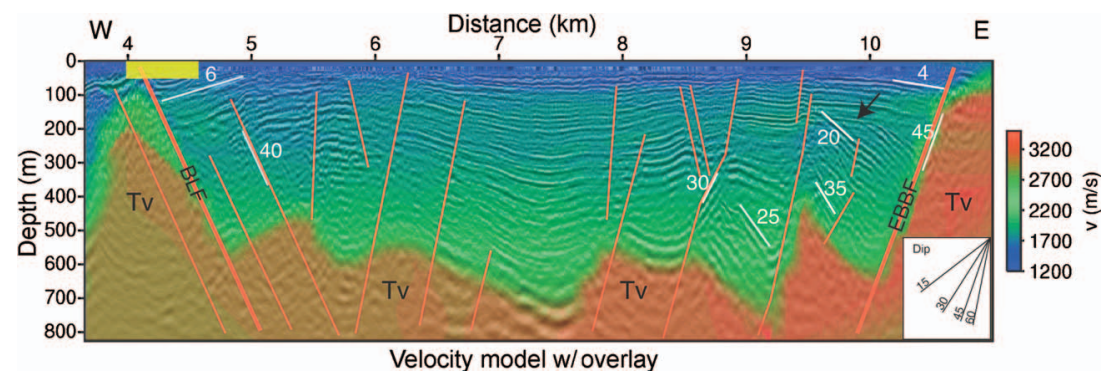

Figure 8. PSDM section with final velocity model and fault interpretations overlain. A number of steeply dipping events are imaged (event and dip are indicated in white), including several fault planes and strata dipping into the faults. The black arrow between 9.5 and $10.5 \mathrm{~km}$ indicates the location of an erosional discontinuity. The region indicated in yellow between 4 and $4.6 \mathrm{~km}$ indicates the approximate projection of the hot springs trend shown in Figure 1. Recent deformation has been most active along the BLF. (Tv Tertiary volcanics). fault system to another (Effimoff and Pinezich, 1981; Liberty et al., 1994). The seismic profiles show clear angular unconformities within these Nevada basins, with changing fault styles above and below the unconformities. The data presented here provide further support for multiphase basin development, perhaps suggesting similar basin evolutions. However, all of these studies lack the dating control required to determine if the change in extensional style occurred at the same time.

\section{CONCLUSIONS}

Overall, PSDM analysis produced good image results at depths ranging from $25 \mathrm{~m}$ to greater than $700 \mathrm{~m}$. Accurately measuring the interval velocity field through reflection tomography proved to be a valuable aid in interpreting depth to basement since a well-defined reflection from the volcanic sequence was not present across much of the section. PSDM proved to have a number of advantages over poststack time migration, particularly in the shallowest $100 \mathrm{~m}$ of the basin. These included accurate datuming, reduced migration artifacts after CIP stacking, and accurate imaging in the presence of large lateral velocity contrasts. While these are the commonly recognized attributes of PSDM, it is rarely utilized in the realm of shallow seismic reflection. With ever-decreasing computational costs, which historically have been a primary limitation of advanced processing in shallow investigations, we believe that PSDM can and should become a standard tool in shallow, high-resolution seismic reflection experiments.

\section{ACKNOWLEDGMENTS}

The National Science Foundation, Idaho EPSCoR, funded this work under Grant EPS-0132626. Boise State University acknowledges support of this research by Landmark Graphics Corporation via the Landmark University Grant Program.

\section{REFERENCES}

Al-Yahya, K. M., 1989, Velocity analysis by iterative profile migration: Geophysics, 54, 718-729.

Blewitt, G. M., D. Coolbaugh, W. Sawatzky, J. D. Holt, and R. Bennett, 2003, Targeting of potential geothermal resources in the Great Basin from regional to basin-scale relationships between geodetic strain and geological structures: Annual Meeting, Geothermal Resources Council Transactions, $3-22$.

Bradford, J. H., 2006, Applying reflection tomography in the post-migration domain to multi-fold GPR data: Geophysics, 71, K1-K8.

Bradford, J. H., and D. S. Sawyer, 2002, Depth characterization of shallow aquifers with seismic reflection - Part II: Prestack depth migration and field examples: Geophysics, 67, 98-109.

Bradford, J. H., D. S. Sawyer, C. A. Zelt, and J. S. Oldow, 1998, Imaging a shallow aquifer in temperate glacial sediments using seismic reflection profiling with DMO processing: Geophysics, 63, 1248-1256.

Cleary, J., I. M. Lange, A. I. Qamar, and H. R. Krouse, 1981, Gravity, isotope, and geochemical study of the Alvord Valley geothermal area, Oregon: Geological Society of America Bulletin, 92, 934-962.

1Davies, K. J., and R. F. King, 1992, The essentials of shallow reflection data processing: Quarterly Journal of Engineering Geology, 25, 191-206.

Deregowski, S. M., 1985, Prestack depth migration by the 2-D boundary integral method: 4th Annual International Meeting, SEG, Expanded Abstracts, 414-417.

- 1986, What is DMO?: First Break, 4, 7-24. 
Effimoff, I., and A. R. Pinezich, 1981, Tertiary structural development of selected valleys based on seismic data; Basin and Range Province, northeastern Nevada: Philosophical Transactions of the Royal Society of London, 300, 435-442.

Evans, J. G., and T. M. Geisler, 2001, Geologic field-trip guide to Steens Mountain Loop Road, Harney County, Oregon: U. S. Geological Survey and U. S. Department of the Interior.

Fairley, J., J. Heffner, and J. Hinds, 2003, Geostatistical evaluation of permeability structure in an active fault zone: Geophysical Research Letters, 30, doi:10.1029/2003GL018064.

Fuller, R. E., 1931, The geomorphology and volcanic sequence of Steens Mountain in southeastern Oregon: University of Washington Publication in Geology, 3, 1-130.

Guo, N., and S. Fagin, 2002, Becoming effective velocity-model builders and depth imagers, part 2: The basics of velocity-model building, examples, and discussion: The Leading Edge, 21, 1210-1216.

Hale, D., 1991, Dip moveout processing: SEG.

Hemphill-Haley, M. A., 1987, Quaternary stratigraphy and late Holocene faulting along the base of the eastern escarpment of Steens Mountain, southeastern Oregon: M.A. thesis, Humboldt State University.

Hess, S., J. H. Bradford, M. Lyle, L. Liberty, R. Myers, and P. Routh, 2004 3D high-resolution geophysical characterization of the Borax Lake Hydrothermal System in the Alvord Basin, southeastern Oregon: 74th Annual International Meeting, SEG, Expanded Abstracts, 1460-1463.

Lafond, C. F., and A. R. Levander, 1993, Migration moveout analysis and depth focusing: Geophysics, 58,91-100.

Liberty, L., 1998, Seismic reflection imaging of a geothermal aquifer in an urban setting: Geophysics, 63, 1285-1294.
Liberty, L., P. L. Heller, and S. B. Smithson, 1994, Seismic reflection evidence for two-phase development of Tertiary basins from east-central Nevada: Geological Society of America Bulletin, 106, 1621-1633.

Morozov, I. B., and A. Levander, 2002, Depth image focusing in traveltime map-based wide-angle migration: Geophysics, 67, 1903-1912.

Narwold, C. F., 2001, Late Quaternary soils and faulting along the Quinn River fault zone, northern Nevada, southeastern Oregon: M.S. thesis, Humboldt State University.

Pasasa, L., F. Wenzel, and P. Zhao, 1998, Prestack Kirchhoff depth migration of shallow seismic data: Geophysics, 63, 1241-1247.

Personius, S. F. and S. A. Mahan, 2005, Unusually low slip rates on the Santa Rosa fault zone, northern Nevada: Bulletin of the Seismological Society of America, 95, 319-333.

Pezzopane, S. K., and R. J. Weldon, 1993, Tectonic role of active faulting in central Oregon: Tectonics, 12, 1140-1169.

Stork, C., 1992, Reflection tomography in the postmigrated domain: Geophysics, 57, 680-692.

Wallace, R. E., 1984, Patterns and timing of late Quaternary faulting in the Great Basin Province and relation to some regional tectonic features: Special section: Fault behavior and the earthquake generation process: Journal of Geophysical Research, 89, 5763-5769.

Wiederhold, H., H. A. Buness, and K. Bram, 1998, Glacial structures in northern Germany revealed by a high-resolution reflection seismic survey: Geophysics, 63, 1265-1272.

Williams, H., and R. R. Compton, 1953, Quicksilver deposits of Steens Mountain and the Pueblo Mountains, southeast Oregon: U. S. Geological Survey Bulletin 995-B. 